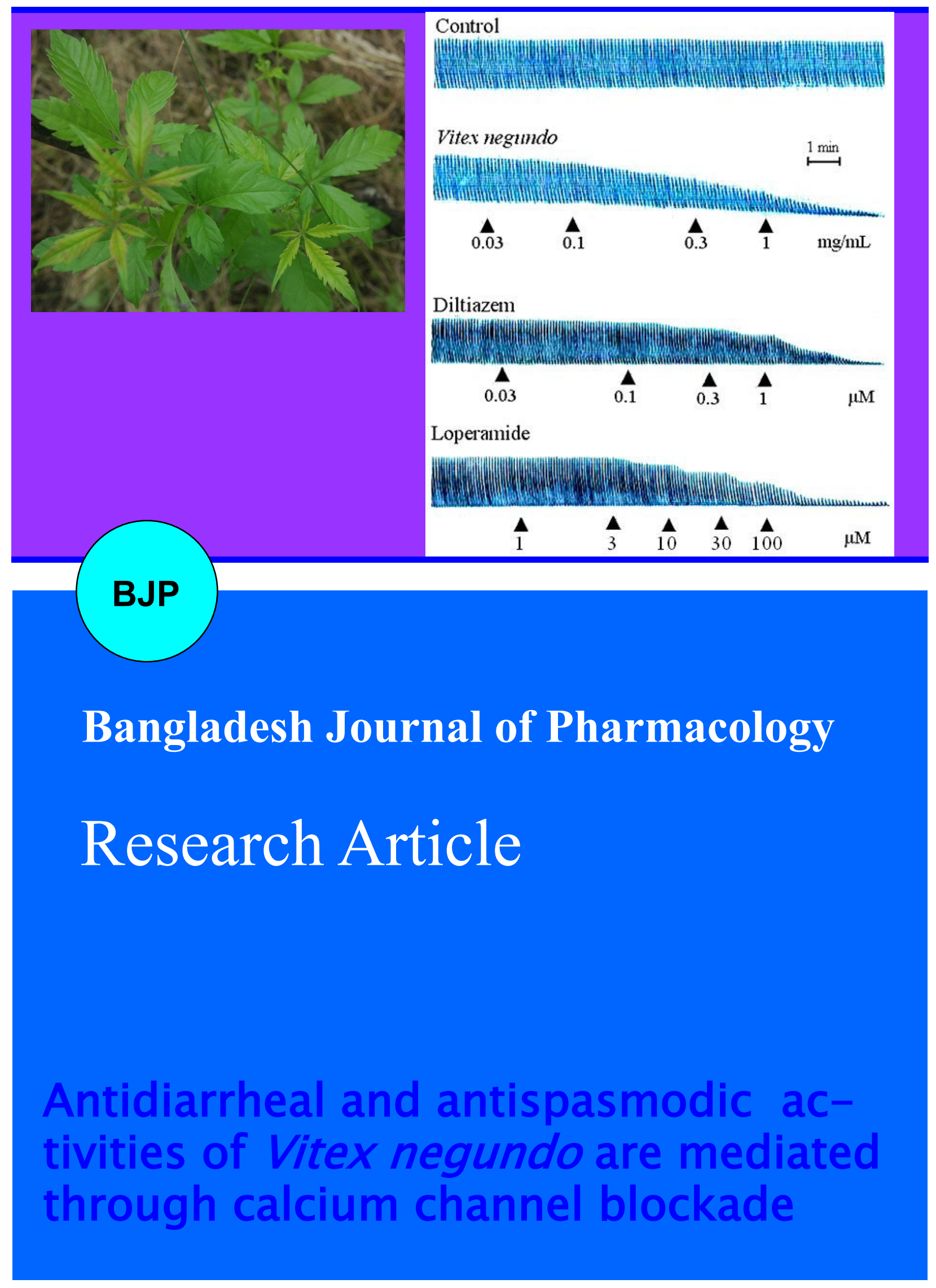




\title{
Antidiarrheal and antispasmodic activities of Vitex negundo are mediated through calcium channel blockade
}

\author{
Munasib Khan',2, Abdul Jabbar Shah'1,3 and Anwarul Hassan Gilani'1,4 \\ ${ }^{1}$ Natural Product Research Unit; Department of Biological and Biomedical Sciences Aga Khan University Medical \\ College, Karachi, Pakistan; ${ }^{2}$ Department of Pharmacy, University of Malakand, Dir Lower, Pakistan; ${ }^{3}$ Department of \\ Pharmaceutical Sciences, COMSATS Institute of Information Technology, University Road, Abbottabad, Pakistan; \\ ${ }^{4}$ Department of Pharmacy, College of Health Sciences, Mekelle University, Mekelle, Ethiopia.
}

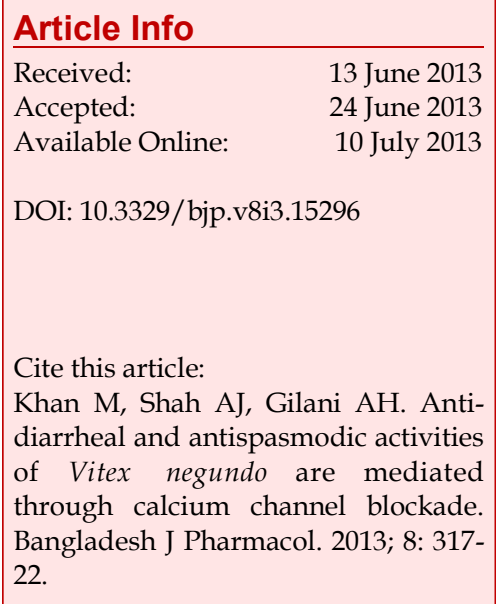

Abstract
Vitex negundo has reputation in the traditional medicine in diarrhea and gut
spasm. This study was carried out to provide possible pharmacological basis
to its medicinal use in hyperactive gut disorders. In castor oil-induced
diarrheal model, the crude extract of $V$. negundo, caused a dose-dependent
protection (53-71\%), similar to loperamide. In isolated rabbit jejunum prepara
-tion, $V$. negundo caused inhibition of spontaneous and high $\mathrm{K}^{+}$-induced
contractions, with EC 50 values of $0.36(0.22-0.61)$ and $1.30 \mathrm{mg} / \mathrm{mL}(0.27-5.89 ;$
$\mathrm{n}=4-5)$, respectively, suggestive of spasmolytic activity, mediated possibly
through calcium channel blockade (CCB). The CCB activity was further
confirmed when pre-treatment of the tissue with $V . n e g u n d o(0.03-0.3$ mg/mL)
caused a rightward shift in the Ca ${ }^{++}$concentration-response curves (CRCs),
similar to diltiazem or loperamide. These data indicate that the antidiarrheal
and spasmolytic effects of the crude extract of $V$. negundo are mediated
through the presence of CCB-like constituent(s).

\section{Introduction}

Vitex negundo Linn., belongs to the family "Verbenaceae" occurs in different parts of Pakistan, such as, Rawalpindi hills, Murree, Muzaffarabad, Mirpur, Lower hazara, Kurram, Swat, Poonch on the bank of streams and water courses (Baquar, 1989). The plant has medicinal reputation in diarrheal and gut spasm, in addition to many other uses, such as, astringent, in rheumatism and joint swelling (Baquar, 1989; Evans, 2006; Shinwari et al., 2003; Usmanghani et al., 1997).

Phyotchemical analysis of the plant revealed the presence of casticin, isoorientin, chrysophenol D, luteolin, p-hydroxybenzoic acid and D-fructose. Additionally, alkaloids, glycosides, flavonoids, sterols, resins, tannins, dimethylether of delphinidin and dimethyl ether of leucocyanidin, rhumanoglucosides and flavone glycolsides have also been found (Hung et al., 2013).
Pharmacologically the plant has been reported to possess anti-inflammatory (Tandon and Gupta, 2006; Puchpangadan et al., 2006), analgesic, antihistaminic (Dharmasiri et al.,2003), hypnotic (Gupta et al., 1999), antioxidant (Munasinghe et al., 2001), anticancer (Diaz et al., 2003), antiandrogenic (Das et al., 2004; Bhargava, 1989), hepatoprotective (Avadhoot and Rana, 1991) antibacterial (Perumal-Samy et al.,1998) and antifungal (Puchpangadan et al., 2006) activities.

Despite the fact that the plant has been studied extensively phytochemically, research on its pharmacological activities in hyperactive gut disorders is lacking. Therefore, this investigation was carried out to provide possible pharmacological basis to the medicinal use of the plant in hyperactive gut disorders, such as diarrhea and spasms. 


\section{Materials and Methods}

Aerial parts of $V$. negundo were collected in District Swat, KhyberPakhtunkhwa., Pakistan, and was authenticated by Assistant Professor Mr. Ilyas Iqbal at the Department of Botany, University of Malakand, Chakdara Dir Lower, Pakistan. A voucher specimen (UOM/BGH/149) was deposited at the herbarium of the same Department. The plant materials was shade dried and were clean up of adulterants and approximately $1 \mathrm{~kg}$ of the pulverized material was soaked in aqueous-methanol $(70 \%)$ at room temperature (25 \pm $2.0^{\circ} \mathrm{C}$ ) for three days with occasional shaking. Then it was filtered through a muslin cloth and then through a filter paper. This procedure of soaking and filtration was repeated twice more.

All the filtrates were combined and evaporated to dryness on a Rotary Evaporator under reduced pressure ($760 \mathrm{mmHg})$ at $35-40^{\circ} \mathrm{C}$ to a thick and dark brown material $(212.74 \mathrm{~g})$, the crude extract of $V$. negundo (Vn.Cr). The approximate yield was $21.274 \%$. Vn.Cr was solubilized in normal saline $(0.9 \% \mathrm{w} / \mathrm{v})$ and distilled water for in vivo and in vitro experiments, respectively.

\section{Preliminary phytochemical analysis}

Crude extract of $V$. negundo was screened for the presence of sapoinns, flavonoids, flavanols, flavones, tannins, phenols, coumarins, sterols, terpenes, alkaloids and anthraquinones by using methods described by Wall et al. (1952).

\section{Drugs and standards}

The following reference chemicals were obtained from the sources specified: Loperamide hydrochloride, acetyl -choline chloride, verapamil hydrochloride, potassium chloride (Sigma Chemical Company, USA) and castor oil (Karachi Chemical Industries, Pakistan). All chemicals used were of the highest purity grade. Stock solutions of all the chemicals were made in distilled water and the dilutions were made fresh in normal saline on the day of the experiment.

\section{Animals}

Experiments performed complied with the rulings of the Institute of Laboratory Animal Resources, Commission on Life Sciences, National Research Council (National Research Council, 1996). Balbc albino mice (20 $-25 \mathrm{~g})$ and local rabbits $(1.5-2 \mathrm{~kg})$ of either sex used in the study were bred and housed in the animal house of Aga Khan University under controlled environment (23 $-25^{\circ} \mathrm{C}$ ). Animals were given tap water ad libitum and a standard diet.

\section{Castor oil-induced diarrhea}

The in vivo antidiarrheal activity of the extract was conducted following the methods previously described
(Awouters et al., 1978; Jebunnessa et al., 2009; Shah et al., 2011a). In the present study Balbc albino mice were fasted for $18 \mathrm{~h}$. The animals were divided in five groups, housed in five steel cages with five mice in each and the bottom of each cage was covered with blotting sheet. The first group received saline $(10 \mathrm{~mL} / \mathrm{kg}$, p.o.) as the vehicle control and so acted as the negative control. The doses of the crude extract of Vitex negundo were selected on a trial basis and administered orally $(100,300$ and $1000 \mathrm{mg} / \mathrm{kg}$ ) by intra-gastric feeding needle to three groups of animals. The fifth group received loperamide $(10 \mathrm{mg} / \mathrm{kg})$ orally, served as positive control. One hour after treatment each animal received $10 \mathrm{~mL} / \mathrm{kg}$ of castor oil orally and was then observed for defecation. Up to 4 hours later the castor oil challenge, the presence of diarrheal droppings was noted in blotting sheets in the individual cages. Percent protection against the castor oil-induced diarrhea was calculated based on the number of dry feces in each cage in comparison to the wet.

\section{Isolated tissue preparations}

The isolated tissue experiments were carried out as previously described (Gilani et al., 2005; Shah et al., 2011b). The animals had free access to water but were fasted for 24 hours before the experiment. The animals were sacrificed by cervical dislocation, the abdomen was cut open and the jejunal portion isolated out. Preparations $2 \mathrm{~cm}$ long were mounted in $10 \mathrm{~mL}$ tissue baths containing Tyrode's solution maintained at $37^{\circ} \mathrm{C}$ and aerated with a mixture of $5 \%$ carbon dioxide in oxygen (carbogen). The composition of Tyrode's, in $\mathrm{mM}$, was: $\mathrm{KCl}$ 2.7, $\mathrm{NaCl} 136.9, \mathrm{MgCl}_{2} 1.1, \mathrm{NaHCO}_{3}$ 11.9, $\mathrm{NaH}_{2} \mathrm{PO}_{4}$ 0.4, Glucose 5.6 and $\mathrm{CaCl}_{2} 1.8$ (pH 7.4). A preload of $1 \mathrm{~g}$ was applied and the tissues kept undisturbed for an equilibrium period of $30 \mathrm{~min}$ after which control responses to a sub-maximal dose of acetylcholine $(0.3 \mu \mathrm{M})$ were obtained and the tissue presumed stable only after the reproducibility of the said responses.

Under these experimental conditions, rabbit jejunum exhibits spontaneous rhythmic contractions, allowing testing the relaxant (spasmolytic) activity directly without the use of an agonist (Gilani et al., 2005).

\section{Determination of calcium antagonist activity}

To assess whether the spasmolytic activity of the test substances was mediated through calcium channel blockade, high concentration of $\mathrm{K}^{+}(80 \mathrm{mM})$, as $\mathrm{KCl}$, was used to depolarize the preparations (Farre et al., 1991). $\mathrm{K}^{+}(80 \mathrm{mM})$ was added to the tissue bath, which produced a sustained contraction. Plant extract and standards were then added in a cumulative fashion to obtain concentration-dependent inhibitory responses (van-Rossum, 1963). The relaxation of intestinal preparations, precontracted with $\mathrm{K}^{+}$, was expressed as percent of the control pre-contraction. 
To confirm the calcium antagonist activity of test substances, the tissue was allowed to stabilize in normal Tyrode's solution, which was then replaced with $\mathrm{Ca}^{++}$-free Tyrode's solution containing EDTA (0.1 $\mathrm{mM}$ ) for $30 \mathrm{~min}$ in order to remove $\mathrm{Ca}^{++}$from the tissues. This solution was further replaced with $\mathrm{K}^{+}$-rich and $\mathrm{Ca}^{++}$-free Tyrode's solution, having the following composition: $\mathrm{KCl} 50, \mathrm{NaCl} 91.04, \mathrm{MgCl}_{2} 1.05, \mathrm{NaHCO}_{3}$ 11.90, $\mathrm{NaH}_{2} \mathrm{PO}_{4}$ 0.42, glucose 5.55 and EDTA $0.1 \mathrm{mM}$. Following an incubation period of $30 \mathrm{~min}$, control concentration-response curves (CRCs) of $\mathrm{CaCl}_{2}$ were obtained. When the control CRCs of $\mathrm{CaCl}_{2}$ were found super-imposable (usually after two cycles), the tissue was pretreated with the plant extract for $60 \mathrm{~min}$ to test the possible calcium channel blocking effect. The CRCs of $\mathrm{CaCl}_{2}$ were reconstructed in the presence of different concentrations of the test material.

\section{Acute toxicity test}

The acute toxicity studies were carried out, as described earlier (Gilani, 1991). Animals were divided in groups of 5 mice each. The test was performed using increasing doses of the plant extracts, given orally, in $10 \mathrm{~mL} / \mathrm{kg}$ volume to different groups serving as test groups. Another group of mice was administered saline (10 $\mathrm{mL} / \mathrm{kg}$, p.o.) as negative control. The mice were allowed food ad libitum and kept under regular observation for $6 \mathrm{~h}$ and the lethality was recorded after $24 \mathrm{~h}$. Toxic effects as gastrointestinal spasms, anorexia, diarrhea and lethargy were also noticed.

\section{Statistics}

All the data expressed are mean \pm standard error of the mean (SEM), and the median effective concentrations (EC50 values) are given with $95 \%$ confidence intervals (CI). The statistical parameter applied is the Student's ttest with $p<0.05$ noted as significantly different (GraphPad Prism).

\section{Results and Discussion}

Based on the medicinal use of $V$. negundo in hyperactive gut disorders, such as diarrhea and spasm (Baquar, 1989; Evans, 2006; Shinwari, et al., 2003; Usmanghani, et al., 1997), its aqueous-methanolic crude extract was tested for the possible antidiarrheal effect in mice. When tested against the castor oil-induced diarrhea in mice, the crude extract of $V$. negundo ( $\mathrm{Vn} . \mathrm{Cr}$ ), like loperamide, a standard antidiarrheal agent (Reynolds et al., 1984), significantly $(\mathrm{p}<0.05)$ inhibited the frequency of defaecation as well as wetting of faeces when compared with untreated group. The crude extract and loperamide reduced greatly the wetness of the faecal droppings and provided around 53-71\% and 93.33\% protection, respectively. The induction of diarrhea by castor oil results from the action of ricinoleic acid formed in the hydrolysis of the oil (Iwao and Terada,
1962), which produces changes in the transport of water and electrolytes resulting in a hypersecretory response and generation of giant contraction of the intestine (Croci et al., 1997). Thus a potential antidiarrheal agent may exhibit its antidiarrheal effect by inhibiting gut motility and/or diarrheal droppings (Croci et al., 1997). The protective effect of the crude extract of $V$. negundo against the castor oil-induced diarrhea in mice, similar to loperamide, suggests that it has either inhibitory effect on contraction or electrolyte out flux. To see its possible inhibitory effect on gut motility, the Vn.Cr was further studied in the in-vitro experiments.

Spontaneously beating isolated rabbit jejunum preparation is used to test possible inhibitory (spasmolytic) effect of test substances without use of a spasmogen (Gilani et al., 2005). When tested in isolated rabbit jejunum preparations, cumulative addition of the Vn.Cr, diltiazem and loperamide, caused concentrationdependent inhibition of the spontaneous contractions (Figure 1), with respective $\mathrm{EC}_{50}$ values of $0.36 \mathrm{mg} / \mathrm{mL}$ (0.22- 0.61), $2.62 \mu \mathrm{M}(0.57-11.95 ; \mathrm{n}=5)$ and $25.80 \mu \mathrm{M}$ (18.80-29.33; n=4) (Figure 2), thus, showing smooth muscle relaxant activity. The contraction of smooth muscle preparations, including rabbit jejunum, is dependent upon an increase in the cytoplasmic free $\left[\mathrm{Ca}^{++}\right]$, which activates the contractile elements (Karaki and Weiss, 1983). The increase in intracellular $\mathrm{Ca}^{++}$ occurs either via influx through voltage-dependant $\mathrm{Ca}^{++}$ channels (VDCs) or its release from intracellular stores. Periodic depolarization and repolarization regulates the spontaneous movements of the intestine and at the height of depolarization, the action potential appears as a rapid influx of $\mathrm{Ca}^{++}$via VDCs (Brading, 1981). Thus the inhibitory effect of the $\mathrm{Vn} . \mathrm{Cr}$ on spontaneous movements of rabbit jejunum may appear to be due to CCB effect mediated, possibly, through interference of $\mathrm{Ca}^{++}$influx through VDCs.

To confirm the involvement of $\mathrm{Ca}^{++}$channels in its spasmolytic effect, a high concentration of $\mathrm{K}^{+}(80 \mathrm{mM})$ was maintained to depolarize the tissue. The Vn.Cr was then added in a cumulative way, where it caused a concentration-dependent relaxation of the induced contractions with an $\mathrm{EC}_{50}$ value of $1.30 \mathrm{mg} / \mathrm{mL}(0.27-$ 5.89; $n=4-5$ ) (Figure 2A), similar to diltiazem (Figure 2B), suggesting that the spasmolytic effect is possibly mediated through CCB. Loperamide also caused concentration-related inhibitory effect against high $\mathrm{K}^{+}$induced contractions with $\mathrm{EC}_{50}$ value of $8.55 \mu \mathrm{M}$ (5.8012.60), as shown in Figure 2C. The crude extract was more potent against $\mathrm{K}^{+}$-induced contractions, similar to diltiazem, a typical characteristic of CCB (Godfraind et al., 1986), thus suggesting that $\mathrm{Vn} . \mathrm{Cr}$ mediates its spasmolytic effect through CCB.

The contractions induced by high $\mathrm{K}^{+}(>30 \mathrm{mM})$ are dependent on the entry of $\mathrm{Ca}^{++}$into the cells through VDCs (Bolton, 1979) and a substance which can inhibit 


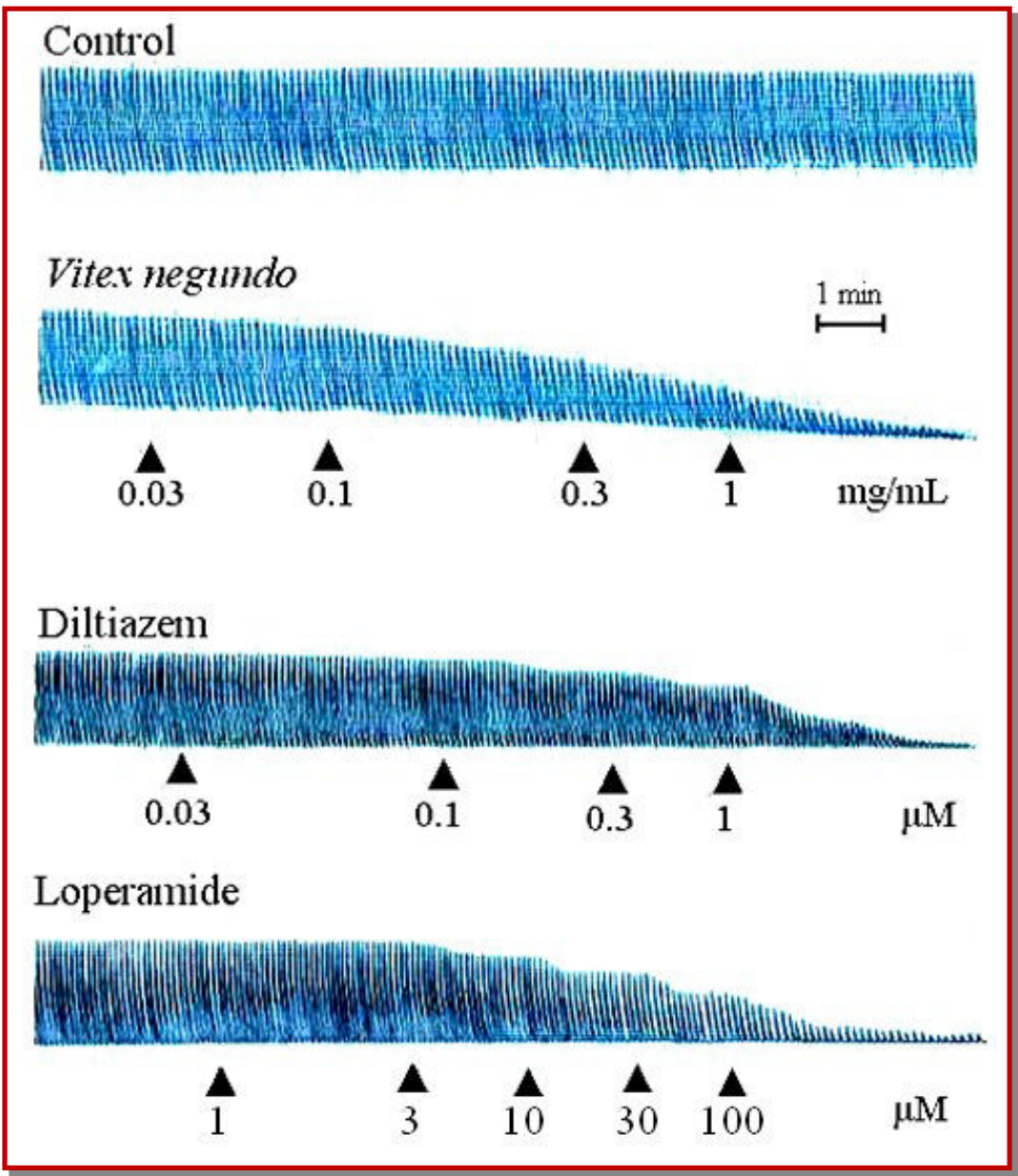

Figure 1: A typical tracing shows the spasmolytic effect of the crude extract of Vitex negundo, diltiazem and loperamide on spontaneous contractions in isolated rabbit jejunum preparations

high $\mathrm{K}^{+}$-induced contractions is therefore, possibly considered to be a CCB (Godfraind et al., 1986). Thus, the inhibition of high $\mathrm{K}^{+}$-induced contractions of rabbit jejunum by $\mathrm{Vn}$.Cr may reflect the restricted $\mathrm{Ca}^{++}$entry via VDCs. This hypothesis was further strengthened when pre-treatment of the tissues with $\mathrm{Vn} . \mathrm{Cr}(0.03-0.3$ $\mathrm{mg} / \mathrm{mL}$ ) caused a rightward shift in the $\mathrm{CaCl}_{2} \mathrm{CRCs}$ (Figure 2D), similar to diltiazem (Figure 2E). Pretreatment of the tissues with loperamide also caused rightward shift in the $\mathrm{CaCl}_{2} \mathrm{CRC}$ (Figure $2 \mathrm{~F}$ ), which is in accordance to its known $\mathrm{CCB}$ effect at antidiarrheal doses (Reynolds et al., 1984). These data indicate that crude extract of $V$. negundo possesses $\mathrm{Ca}^{++}$channel blocking effect similar to diltiazem. These findings provide pharmacological rationale to the antidiarrheal and antispasmodic effects of $V$. negundo because CCBs are considered useful in diarrhea and gut spasms (Brunton, 1996). The presence of flavonoids, and tannins, revealed by preliminary phytochemical analysis, support the CCB effect of the plant extract because plant derived flavonoids (Zhu et al., 1997) and tannins (Zhu et al., 2005) have been found to posses CCB effect, which might be the active candidate(s) responsible for its medicinal use in diarrhea and gut spasm, though additional mechanisms cannot be ruled out.

In acute toxicity test the crude extract was found safe up to the dose of $10 \mathrm{~g} / \mathrm{kg}$, indicates safety of the plant, though safety profile for chronic use needs further studies.

\section{Conclusion}

The crude extract of $V$. negundo possesses antidiarrheal and anti-spasmodic effects mediated through calcium channel blockade and provides possible pharmacological base to its medicinal use in hyperactive gut disorders, such as diarrhea and gut spasms.

\section{Acknowledgement}

This study was supported in part by Pakistan Science Foundation. 


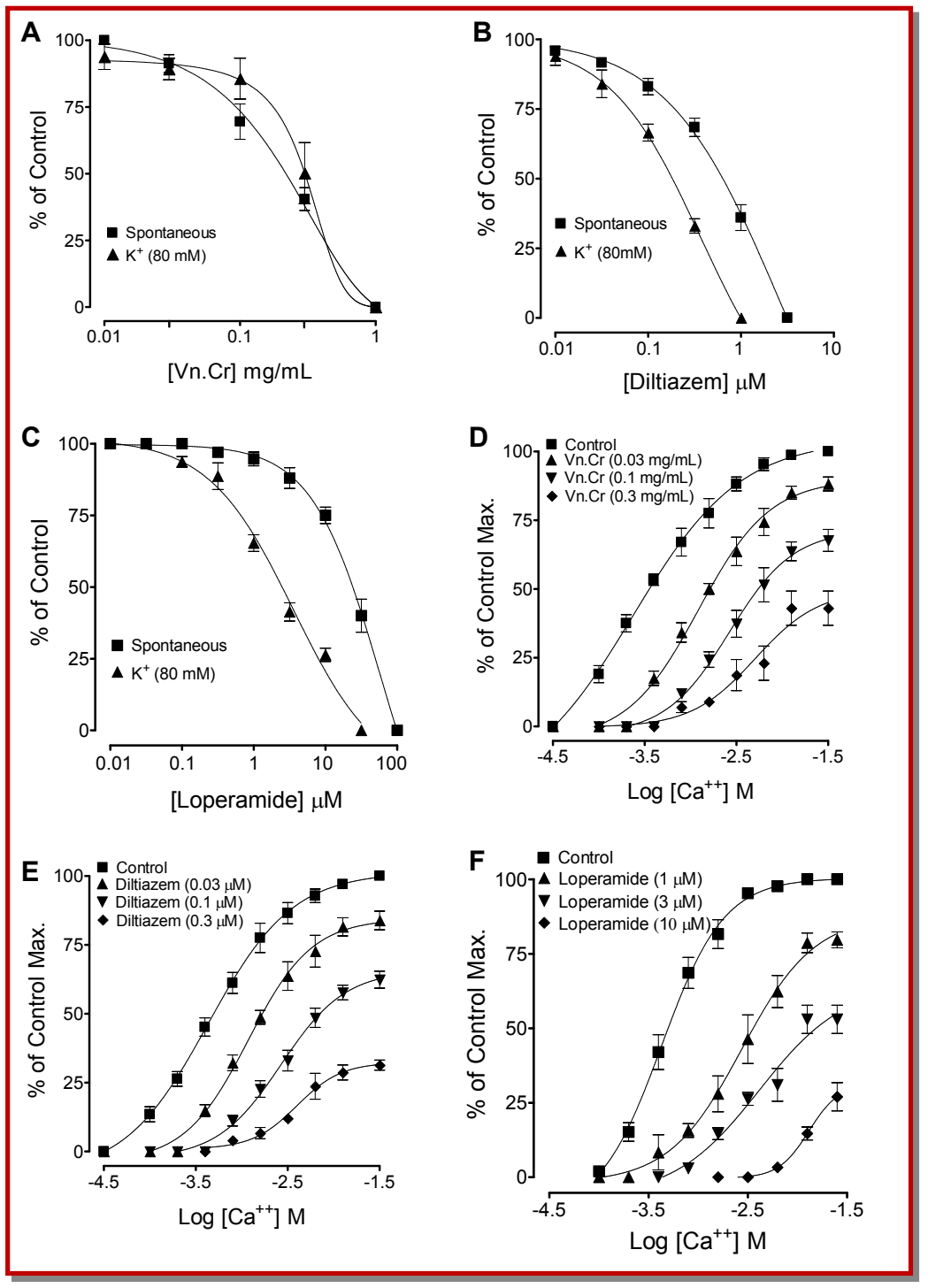

Figure 2: Concentration-response curves of; (A) the crude extract of Vitex negundo (Vn.Cr), (B) diltiazem and (C) loperamide on spontaneous and high $\mathrm{K}^{+}(80 \mathrm{mM})$-induced contractions. Figures $\mathrm{D}, \mathrm{E}$ and $\mathrm{F}$ depict the effect on $\mathrm{CaCl} 2$ concentration-response curves in the absence and presence of different concentrations of the $\mathrm{Vn}$. Cr, diltiazem and loperamide, respectively, in isolated rabbit jejunum preparations. Values shown are \pm SEM $(n=4-6)$

\section{References}

Avadhoot Y, Rana AC. Hepatoprotective effect of Vitex negundo against carbon tetrachloride-induced liver damage. Arch Pharm Res. 1991; 14: 96-98.

Awouters F, Niemegeers CJE, Lenaerts FM, Janssen PAJ. Delay of castor oil diarrhea in rats, a new way to evaluate inhibitors of prostaglandin biosynthesis. J Pharm Pharmacol. 1978; 30: 41-45.

Baquar SR. Medicinal and poisonous plants of Pakistan. Karachi, Printas, 1989, pp 472-73.

Bhargava SK. Antiandrogenic effects of a flavonoid-rich fraction of Vitex negundo seeds: A histological and biochemical study in dogs. J Ethnopharmacol. 1989; 27: 327-39.

Brading AF. How do drugs initiate contraction in smooth muscles? TIPS. 1981; 2: 261-65.

Bolton TB. Mechanism of action of transmitters and other substances on smooth muscles. Physiol Rev. 1979; 59: 606718.

Brunton LL. Agents affecting gastrointestinal water flux and motility; emesis and antiemetics; bile acids and pancreatic enzymes. In: Goodman and Gillman's The Pharmacological Basis of Therapeutics. Hardman, JG, Limbird, LE, Molinoff, PB (eds). 9th ed. New York, McGraw Hill, 1996, pp 917-36.

Croci T, Landi M, Elmonds-Alt X, Le Fur G, Maffrand JP, Manara L. Role of tachykinins in castor oil induced diarrhea in rats. Br J Pharmacol. 1997; 121: 375-80.

Das S, Parveen S, Kundra CP, Pereira BMJ. Reproduction in male rats is vulnerable to treatment with the flavonoid-rich seed extracts of Vitex negundo. Phytother Res. 2004; 18: 8-13. 
Diaz F, Chavez D, Lee D, Mi Q, Chai HB, Tan GT, Kardono LB, Riswan S, Fairchild CR, Wild R, Farnsworth NR, Cordell GA, Pezzuto JM, Kinghorn AD. Cytotoxic flavone analogues of vitexicarpin, a constituent of the leaves of Vitex negundo. J Nat Prod. 2003; 66: 865-67.

Evans WC. Trease and Evans Pharmacognosy. $15^{\text {th }}$ ed. London, W B. Saunders, 2006.

Farre AJ, Columbo M, Fort M, Gutierrez B. Differential effects of various $\mathrm{Ca}^{++}$antagonists. Gen Pharmacol. 1991; 22: 17781.

Gilani AH, Ghayur MN, Khalid A, Haq Z, Choudhary MI, Rahman A. Presence of antispasmodic, antidiarrheal, antisecretory, calcium antagonist, acetylcholinesterase inhibitory steroidal alkaloids in Sarcococca saligna. Planta Med. 2005; 71: 1-6.

Gilani AH, Shah AJ, Manzoor A, Shaheen F. Antispasmodic effect of Acorus calamus Linn., is mediated through calcium channel blockade. Phytother Res. 2006; 20: 1080-84.

Godfraind T, Miller R, Wibo M. Calcium antagonism and calcium entry blockade. Pharmacol Rev. 1986; 38: 321-416.

Gupta M, Mazumder UK, Bhawal SR. CNS activity of Vitex negundo Linn. in mice. Indian J Exp Biol. 1999; 37: 143-46.

Huang J, Wang GC, Wang CH, Huang XJ, Ye WC. Two new glycosides from Vitex negundo. Nat Prod Res. 2013 Jan 29 (in press).

Iwao I, Terada Y. On the mechanism of diarrhea due to castor oil. Jpn J Pharmacol. 1962; 12: 137-45.

Karaki H, Weiss G. Mini-review: Calcium release in smooth muscles. Life Sci. 1983; 42: 111-22.

Jebunnessa, Uddin SB, Mahabub-Uz-Zaman M, Akter R, Ahmed NU. Antidiarrheal activity of ethanolic bark extract of Mitragyna diversifolia. Bangladesh J Pharmacol. 2009; 2: $144-46$.

Khan A, Gilani AH. Antidiarrheal and bronchodilator potential of olive extract. Lat Am J Pharm. 2011; 30: 5-9.

Munasinghe JTC, Seneviratne CK, Thabrew MI, Abeysekera AM. Antiradical and anti-lipoperoxidative effects of some plant extracts used by Sri Lankan traditional medical practitioners for cardioprotection. Phytother Res. 2001; 15: $519-23$.
National Research Council, Guide for the care and use of laboratory animals. National Academy Press, Washington DC, 1996.

Perumal-Samy R, Ignacimuthu S, Sen A. Screening of 34 Indian medicinal plants for antibacterial properties. J Ethnopharmacol. 1998; 62: 173-82.

Reynolds IJ, Gould RJ, Synder SH. Loperamide blockade of calcium channel as mechanism for antidiarrheal effects. J Exp Pharmacol Ther. 1984; 231: 628-32.

Shah AJ, Sabira B, Syed IH, Syed NA, Bina SS, Gilani AH. Pharmacological basis for the medicinal use of Psidium guajava leaves in hyperactive gut disorders. Bangladesh J Pharmacol. 2011a; 6: 100-05.

Shah AJ, Mudassar A, Zaidi, Hassan S, Hamidullah, Gilani AH. Antidiarrheal and antispasmodic activities of Vincetoxicum stocksii are mediated through calcium channel blockade. Bangladesh J Pharmacol. 2011b; 6: 46-50.

Shinwari ZA, Khan AA, Nakaika T. Medicinal and other useful plant of District Swat Pakistan, 2003, p 106.

Tandon VR, Gupta RK. Vitex negundo Linn (Vn) leaf extract as an adjuvant therapy to standard anti-inflammatory drugs. Indian J Med Res. 2006; 124: 447-50.

Usmanghani K, Saeed A, Alam MT. Indusyunic Medicine. Karachi, University Of Karachi Press, 1997, pp 441-42.

van-Rossum JM. Cumulative dose-response curves. II. Techniques for the making of dose-response curves in isolated organs and the evaluation of drug parameters. Arch Int Pharmacodyn. 1963; 143: 299-330.

Wall ME, Eddy CR, McClenna ML, Klump ME. Detection and estimation of steroid and sapogenins in plant tissue. Anal Chem. 1952; 24: 1337-42.

Zhu M, Phillipson JD, Greengrass PM, Bowery NE, Cai Y. Plant polyphenols: Biologically active compounds or nonselective binders to proteins? Phytochemistry 1997; 44: 44147.

Zhu F, Huang B, Hu CY, Jiang QY, Lu ZG, Lu M, Wang MH, Gong M, Qiao CP, Chen W, Huang PH. Effects of total flavonoids of Hippophae rhamnoides L. on intracellular free calcium in cultured vascular smooth muscle cells of spontaneously hypertensive rats and Wistar-Kyoto rats. Chin J Integr Med. 2005; 11: 287-92.
Author Info
Anwarul Hassan Gilani (Principal contact)
e-mail: anwar.gilani@aku.edu

e-mail: anwar.gilani@aku.edu 